\title{
Occupational Credentials and Job Qualities of Direct Care Workers: Implications for Labor Shortages
}

\author{
Jeounghee $\operatorname{Kim}^{1}$ (1)
}

Accepted: 13 November 2020 / Published online: 15 December 2020

(C) The Author(s), under exclusive licence to Springer Science+Business Media, LLC part of Springer Nature 2020

\begin{abstract}
Occupational training and credentialing requirements for direct care workers were in place for consumers' health and safety, but their effects on job qualities and labor shortages in the direct care industry have been controversial. Using a nationally representative sample of psychiatric, nursing, and home health aides, a series of Average Treatment Effect models were analyzed to examine the effects of occupational credentials on various measures of job qualities. The findings revealed that credentialholding was related to higher annual earnings and increased probability of working fulltime, year-round, and having access to employer-provided health insurance and retirement savings plans. The positive effects, however, were modest in size and suggested that, given the current wage and benefit levels for direct care workers, training and credential requirements cannot be the key to resolving job quality and labor shortage issues in the direct care industry. Implications of these findings and alternative ways to address the issues were discussed.
\end{abstract}

Keywords Occupational credential · Direct care workers · Long-term care workforce · Low-wage workers $\cdot$ Home health

\section{Introduction}

There were about 3.3 million nursing assistants, home health aides, psychiatric aides, and personal care aides in 2014 in the United States, taking more than $20 \%$ of the healthcare workforce in the country (U.S. General Accountability Office 2016). These direct service workers provide long-term care services and support to millions of patients with physical and mental illness in an institutional setting (i.e., hospitals and mental health and nursing facilities, community-based residential and non-residential facilities) or at patients' homes (Kelly et al. 2013; Nguyen 2017). They are required to

Jeounghee Kim

jeoukim@ssw.rutgers.edu

1 School of Social Work, Rutgers, the State University of New Jersey, New Brunswick, NJ, USA 
be trained and credentialed (certified or licensed) when they are employed by nursing homes or agencies that participate in Medicare or Medicaid for long-term care patients or individuals with post-acute care needs.

Although direct care job is one of the five fastest-growing jobs in the country (Bureau of Labor Statistics 2019), it is known to be poor qualities with insufficient work hours, low pays and few employment benefits, and limited career advancement opportunities. The 2017 median hourly wages for home health aides, nursing assistants, and psychiatric aides were $\$ 11.16, \$ 13.23$, and $\$ 13.04$, respectively, with the median annual earnings ranging between $\$ 23,000$ and $\$ 27,000$ (U.S. Bureau of Labor Statistics 2018). Data from the National Compensation Survey showed that over $90 \%$ of fulltime direct care workers received health insurance, and $71 \%$ of them had access to retirement savings in 2015. In contrast, less than $23 \%$ of part-time direct care workers had access to health insurance, and less than $36 \%$ of them had access to retirement saving plans in the same year (U.S. Government Accountability Office 2016). With limited earnings and access to employment benefits, many of these workers rely on means-tested benefits such as the Supplemental Nutritional Assistance Program, Medicaid, and housing assistance (Paraprofessional Healthcare Institute 2018). Poor job qualities of direct care workers make it difficult to recruit and retain the workforce, and worker shortage is one of the pressing agendas in the industry (Dawson 2016; Folbre 2006).

Of many efforts made to improve the job qualities of the workforce including labor organizing, legislative reforms, state Medicare reforms (Kelly et al. 2013), occupational training and credentialing have been debated as a key solution that has the potential to address not only job quality and worker retention, but also service quality (Appelbaum and Leana 2011; Lerman et al. 2014; Osterman 2008, 2019). Occupational training and credentialing are theorized to help improve direct care workers' job qualities by improving workers' occupation-specific knowledge and skills, which, in turn, can increase their competency in and commitment to the jobs, thereby, facilitating higher pays and compensations (Kleiner and Krueger 2010; Lerman et al. 2014). As the Institute of Medicine (2008) recommended, increasing minimum training and credentialing standards further lead to expanding the roles of the workforce beyond the traditional scope of practice, which also has the potential to increase job qualities.

An opposing view, however, exists within the direct care industry that training and credentialing requirements hinder recruitment and contribute to worker shortages by limiting the pool of eligible job candidates and slowing down the hiring process when candidates are not already trained and credentialed (Severns 2020). This view made its way during the recent Covid-19 pandemic as the Center for Medicare and Medicaid Services (CMS) issued a blanket waiver to allow nursing centers to temporarily employ nursing aides with 8-h online training and to address worker shortages (American Health Care Association and National Center for Assisted Living 2020). Despite the importance and conflicting perspectives on the role of training and occupational credentials for direct care workers, theoretical explanations and empirical evidence that support its effects on job qualities are rare (Dill and Morgan 2018).

The purpose of this study is, therefore, to address this gap in the literature and provide empirical evidence on the effects of occupational credentials on the following five job quality measures for nursing, psychiatric, and home health aides: (1) full-time weekly work status, (2) year-round work status, (3) access to employer-provided health 
insurance, (4) access to a retirement saving plan, and (5) annual earnings. The analyses revealed that although credential-holding was related to higher annual earnings and increased probability of working full-time, year-round, and having access to employerprovided health insurance and retirement savings plans, the effects were modest in size, casting doubt on the assertion that occupational training and credentialing can substantially improve direct care workers' job qualities and mitigate labor shortage in the fastgrowing industry. To the author's best knowledge, this study provides the first empirical evidence on the effects of occupational credentials on a comprehensive set of job qualities of direct care workers.

\section{Credential Requirements for Direct Care Workers}

The federal government mandates that direct care workers employed by home health agencies or nursing homes whose services are reimbursed by Medicare or Medicaid should receive a minimum of $75 \mathrm{~h}$ of training, including $16 \mathrm{~h}$ of supervised practical (clinical) training, and be certified by demonstrating their competency through evaluation (42 CFR 484.36). Nurse aides are trained and certified for basic nursing skills, personal care skills, mental health and social service skills, skills to care for cognitively impaired residents, basic restorative skills, and residents' rights. Training and certification for home health aides focus more on areas that include communication skills; maintenance of a clean, safe, and healthy environment; recognition of, and procedures for, emergencies; safe transfer techniques; the normal range of motion and positioning; and basic nutrition (Institute of Medicine 2008). According to the Institute of Medicine (2008), the 75-h training requirement is low compared to other service professions. California, for example, requires significantly more hours of training for manicurists (350 h), skin-care specialists (600 h), and hair stylists (1500 h). Furthermore, direct care workers outside the Medicare or Medicaid environment have no federally required minimum hours of training or competency evaluation process (Institute of Medicine 2008). The workers who work for private companies or directly hired by patients as independent providers are not required to go through any training or certification process although they have the option to be trained and certified by state requirements.

The training and credentialing requirements vary greatly by state. Nurse aides, for instance, are required to receive a minimum of 120 or more hours of training in the District of Columbia and in the following 13 States: Maine, Missouri, Oregon, California, Delaware, Alaska, West Virginia, Arizona, Florida, Illinois, Virginia, Indiana, and Wisconsin. In 20 other states, however, they are required to receive only the federally required minimum of $75 \mathrm{~h}$ of training to be certified (Paraprofessional Healthcare Institute 2016a). Similarly, while home health aides in Maine, Alaska, California, Idaho, Illinois, and Wisconsin are required to receive between 120 and $180 \mathrm{~h}$ of training (with a minimum of 20 to $80 \mathrm{~h}$ of clinical training) and be certified, those in the remaining 34 states and the District of Columbia are required to take only the federally required minimum for certification (Paraprofessional Healthcare Institute 2016b). In other states, home health aides must be certified nurse aides (e.g., Maine, Wisconsin, Rhode Island, New Hampshire, Maryland, Washington, etc.) (Paraprofessional Healthcare Institute 2016b). As discussed above, the federal training and credentialing requirements were recently waived due to the Covid-19 pandemic, 
and at least three states (Connecticut, Maryland, and Georgia) adopted the online training and certification (Severns 2020).

\section{Effects of Occupational Credentials on Job Qualities}

Occupational credentials such as licenses and certifications have the potential to improve workers' labor market outcomes through the following three effects: (1) human capital effect, (2) occupational closure effect, and (3) signaling (or sheepskin) effect. Credentials can improve workers' occupation-specific skills and knowledge through training and credentialing processes (the so-called 'human capital effect'). The process improves direct care workers' sense of confidence and job satisfaction, which can help increase their job retention and clients' satisfaction (Menne et al. 2007). Direct care workers with more knowledge, skills, and job satisfaction are likely to have a long history with the same clients and may be able to command higher wages, more hours of work, and greater earnings from their employers.

Occupational training and credentialing can also increase earnings by limiting the supply of qualified workers that can enter the occupation (the so-called 'closure effect'). Entrance to license-based occupations is most tightly closed, and the regulation generates earnings premiums for credential holders (Kleiner and Krueger 2010). Furthermore, Law and Marks (2009) and Blair and Chung (2018) argued that occupational credentials can positively affect labor market outcomes of historically disadvantaged workers by signaling workers' quality particularly for occupations for which the quality information is difficult to come by (the so-called 'signaling effect'). The job market signaling effects of occupational credentials are positive for women and racial minorities as credential holding is associated with a $7.9 \%$ wage premium for White women and a $6.2 \%$ wage premium for African American women (Blair and Chung 2018). Scholars like Redbird (2017), however, wrote that credentials are not associated with earnings premiums although they may increase employment among women, historically disadvantaged groups, and immigrants by helping them bypass questions of employability with state or industry-endorsed quality signals.

Empirical estimates of the credential-related labor market premiums are mostly concentrated on wages or earnings. Gittleman et al. (2018) similarly found that licensed workers earned approximately $6.2 \%$ higher wages on average than unlicensed and uncertified workers and that certified workers earned $7.3 \%$ higher wages on average than unlicensed and uncertified workers (Gittleman et al. 2018). Kim and Chatterji (2020) examined the effects of job-required credentials for workers without a college degree, a population relevant to this study, and reported that credentials are associated with about a $4.8 \%$ increase in weekly earnings for women with high school education and a $7.1 \%$ increase for women with some college education but without a degree. One exception was the findings of Albert (2017), who reported that credential-related earnings premiums for young workers are as high as $18 \%$.

Empirical evidence exists for occupation-specific wages and the earnings premiums of occupational credentials, and the size of premiums are in general greater than $10 \%$ for the three occupations, for which the evidence is available (Kleiner and Park 2010; Pizzola and Tabarrok 2017; Thornton and Timmons 2013). More specifically, dental hygienists, when allowed to be self-employed with their credentials, have about $10 \%$ 
higher earnings (Kleiner and Park 2010). Licensing in the funeral services industry is related to a wage premium of 11-12\% (Pizzola and Tabarrok 2017). Message therapists in states with licensing receive an earnings premium of as much as $16.2 \%$ (Thornton and Timmons 2013). Unlike these relatively large effects, however, Timmons and Thornton (2008) who used instrumental variables estimation for radiologic technologists reported that licensing is related to a $6.9 \%$ wage premium.

Besides the evidence on wages and earnings premiums and a small number of specific occupations, the effect of occupational credentials on labor market outcomes other than wages or earnings is relatively unknown. It is also not clear if the effects of credentials are positive for direct care workers. As indicated above, for direct care workers there is an artificial wage ceiling associated with a third party-payer system of long-term care services and support by Medicare, Medicaid, worker's compensation, or long-term care insurance. Although states and health agencies exercise discretion over workers' wages and employment benefits, the third-party payer system suppresses workers' wages and benefits and leaves little room for training and credentials to improve them (Dawson and Surpin 2001; MacAdam 1993; Stone 2004).

Perhaps, occupational training and credentials positively affect direct care workers' job qualities by dictating where they work, which, in turn, influence their hours of work, access to health insurance and retirement saving plans, and earnings. Because hospitals and nursing homes are most likely to participate in Medicare or Medicaid, they are required to impose credential requirements on direct care workers. Therefore, credentialed workers are more likely than their non-credentialed counterparts to obtain a job at hospitals or skilled nursing facilities, or Medicare-certified home care agencies, where wages and employment benefits are relatively more generous than other places. According to the U.S. Bureau of Labor Statistics (2018), direct care workers who work at skilled nursing facilities $(\$ 26,200)$ and psychiatric and substance abuse hospitals are paid more $(\$ 37,550)$ than aids in other service industries (e.g. home health care service industry at $\$ 25,000$ ). Literature noted that direct care workers' employment settings affect their access to employment benefits. Hospital aides who work for employers with the federal health insurance mandate for having more than 50 employees, for example, are more likely to have employer-provided health insurance coverage, compared to home health aides who may work for small home health agencies (Smith and Baughman 2007).

It may even be possible that credentials can help expand direct care workers' tasks and responsibilities, which may call for increased pay rate or work hours (Franzosa et al. 2018). Home health aides' professional standards and job responsibilities vary by state although all states comply with the basic federal regulations (McMullen et al. 2015). In New Jersey, for example, a certified home health aide is allowed to administer medications when a registered nurse delegates the administration of a specific medication to the aid (New Jersey Board of Nursing 2020). It would be important to investigate if occupational credentials can lead to increased job qualities potentially via expanded tasks or responsibilities.

Building upon the theoretical understanding and empirical evidence discussed above, this study aims to examine the effects of direct care workers' occupational credentials on the following measures of job quality: (1) full-time weekly work, (2) year-round work, (3) access to employer-provided health insurance, (4) access to a retirement saving plan, and (5) annual earnings. It is hypothesized that holding an occupational credential improves all measures of job quality included in the study. 


\section{Methods}

\section{Data and Sample}

This study used a nationally representative sample of home health aides, nurse aides, or psychiatric aides from the 2017-2019 Annual Social and Economic Supplement (ASEC) of the Current Population Survey (CPS). CPS is a monthly survey of about 60,000 U.S. households conducted by the Census Bureau for the Bureau of Labor Statistics to collect basic employment and demographic information (U.S. Census Bureau 2020). The ASEC supplement survey takes place in March every year to collect detailed data on respondents' occupation, industry, occupational credential holding, employment, and job quality measures. Although CPS began collecting occupational credential data starting from 2015, this study pooled only 2017, 2018, and 2019 data files because 2017 was the first year when all the occupational credential variables were fully incorporated.

Using the detailed 4-digit occupation classification codes (NAICS), all nursing, psychiatric, and home health aides employed in each survey year were selected from the data files. It is important to note that distinguishing home health aides from nurse aides or psychiatric aides was not possible in the CPS data. The direct care workers who were business owners of home health agencies (i.e., incorporated business owners) and administrators of the agencies were identified by cross-referencing occupation, industry, and self-employment variables and excluded from the analysis. A total of 3494 direct care workers were chosen as the final analytic sample of this study.

\section{Variables and Measures}

The major independent variable, occupational credentials, measured whether or not the sample direct care workers held an active certification (or license) required by their jobs either legally or by an employer. The CPS data on occupational credentials are based on the respondents' self-report, and although it is likely that the data have measurement errors, the U.S. Bureau of Labor Statistics, which cross-checked the pilot survey data against administrative data of a small-seeded sample, determined that the measurement errors were within an acceptable range and insignificant among those employed (Allard 2016).

The dependent variables of this study, job quality measures, included the following five variables: (1) full-time weekly work status (i.e., working at least $35 \mathrm{~h}$ per week); (2) year-round work status (i.e., working at least 50 weeks a year); (3) having access to employer-provided health insurance; (4) having access to an employer-provided retirement plan; and (5) annual person-level gross earnings before any deduction, adjusted for inflation in 2019 and log-transformed.

Previous studies reported that most workers in direct care occupations are non-white mothers who support their families with low incomes balancing paid work and family responsibilities (e.g., Stone and Dawson 2008). Based on the literature that examined direct care workers' job qualities, workers' demographic characteristics, measured categorically in the following ways, were examined for their effects on job quality (Temple et al. 2009): (1) age in years (less than 24 years old; 25-34; 35-44; 45-54; 5564; and 65 or older); (2) gender (male or female), (3) race and ethnicity (White, African 
American, Hispanic, and other); (4) marital status (married or not); (5) parental status (yes or no); (6) immigration and citizenship status (native-born citizens, naturalized citizens, and non-citizens); and (7) educational attainment (less than high school, high school education, some college, and college or more).

Using the industry variable, the employment setting of direct care workers was broken down into the following eight categories: (1) nursing care facilities, (2) home health care services, (3) hospitals, (4) residential care facilities, (5) other health care services, (6) individual and family services, (7) outpatient care centers, and (8) all other industries. To control for the effect of type of employers on job quality measures, three types of employers - private agencies, state or local governments, and household employers or self-employed - were measured and included in the analyses (Kim 2020). State variations in training and credentialing requirements for home health aides were controlled for. Additionally, the regional difference in the cost of living, and any state-level differences in job qualities were controlled for with a state-fixed effect by including the sample workers' states of residence in the analysis.

\section{Average Treatment Effect Models}

This study investigated five outcomes of occupational credentials - the probability of accessing employer-provided health insurance, the probability of having an employerprovided retirement saving plan, working full-time, working year-round, and the amount of annual earning - which can be presented in the basic reduced form specification as below. These outcomes are modeled as functions of occupational credential holding $(C)$, demographic characteristics $(D)$ that included age, gender, race and ethnicity, marital status, parent status, immigration, and citizenship status, educational attainment $(E)$, employment setting and the type of employers $(S)$, state rules on the required hours of training for home health aides' credentials $(R)$, state and year specific conditions measured in state and year fixed effects $(F)$, direct care workers' $\operatorname{traits}(T)$, and all other unobserved factors $(\varepsilon)$ that influence the outcomes under study.

$$
y=\alpha+\beta_{1} C+\beta_{2} D+\beta_{3} E+\beta_{4} S+\beta_{5} R+\beta_{6} F+\beta_{7} T+\varepsilon
$$

While some of earlier studies of occupational credentials and their effects on labor market outcomes used OLS regression models (e.g., Kleiner and Krueger 2010), more recent studies recognized the major limitations of simple regression models and improved on the methods to account for selection bias based on both workers' traits (Lamm and Yung 2017). This study used Average Treatment Effect (ATE) models because of their strength in controlling for systemic differences in observable traits of direct care workers, which would affect not only their job qualities but also their credential status. Some direct care workers 'selected' to attain credentials, and the traits that influenced their choice would also affect their job qualities (Albert 2017; Pizzola and Tabarrok 2017). These so-called pretreatment characteristics need to be controlled for to remove their confounding effects on job qualities. In an ATE model, a Propensity Score Matching (PSM) model is used to control for pretreatment characteristics, and the resulting scores are used to make the so-called treated group (those holding a credential) and controlled group (those without a credential) compatible. The propensity score is also a balancing score. To assess if the balance between the treated and comparison 
groups was improved by the PSM model, the weighted and unweighted standardized mean differences and variance ratios for the propensity score model are assessed, and more discussion is provided in the Results section below (SAS 2016).

In an ATE modeling, the PSM model of credential holding and the outcome model of job qualities are specified separately, but then their results are combined to estimate the average causal effects of treatment (occupational credentials) on the outcomes under study (the five measures of job qualities). The results of ATE models are known to provide valid causal interpretations even with observational data (SAS 2016). Nevertheless, it is important to note that the models control for workers' observable traits only and cannot control for unobservable traits that may also influence the outcomes.

$$
\mathrm{ATE}=\mu_{1}-\mu_{0}=E[Y(1)]-E[Y(0)]
$$

An ATE model can be expressed as above, where $\mu_{1}=E[Y(1)]$ and $\mu_{0}=E[Y(0)]$ are potential outcomes means for credentialed (the treated) and non-credentialed (the control) direct care workers. Augmented Inverse Probability Weight (AIPW) was used to combine the models of the probability of holding a credential $(C)$ and of each of the job quality outcomes. It produces doubly robust unbiased estimates for the outcome means and the ATE even if one of the models is misspecified (Lamm and Yung 2017). The inverse probability weighting of the AIPW method is based on modeling the probability of holding an occupational credential. For a set of covariates, $\mathrm{X}$, the conditional probability of holding a credential $(C)$, also called the propensity score, is as follows (the method that predicts $e(\mathrm{x})$ is called the Propensity Score Model, PSM) (Lamm and Yung 2017).

$$
e(\mathrm{x})=\operatorname{Pr}(C=1 \mid \mathrm{x})
$$

The inverse probability weight for an observation is equal to the following.

$$
\frac{1}{\operatorname{Pr}(C=c \mid \mathrm{x})}=\frac{c}{e(\mathrm{x})}+\frac{1-c}{1-e(\mathrm{x})}
$$

Brookhart et al. (2006) warned that, for a PSM, including variables related to the probability of treatment but not to an outcome leads to decreased precision in the estimates and that variables that may not be related to the probability of treatment but related to outcomes would increase the precision of the model estimates. Following this guideline, the PSM of each job quality outcome included variables crucial to the job quality measure. That is, full-time and year-round work statuses were controlled for in the PSM model of the employment benefits models (i.e., the benefits are available only for full-time year-round employees, Smith and Baughman 2007). For the PSM model of the earnings outcome model, both weekly hours of work and the number of annual workweeks were controlled for because annual earnings are the product of wage rates and the number of work hours. For all PSM models, gender, age, race and ethnicity, education, employment setting, the state-level fixed effect were included to predict the probability of obtaining a credential. The variable for states' rules on the required hours of training for home health aides' credentials was not included in the PSM models because, when combined with state-level fixed effects, the covariate balance of the variable in the PSM models did not improve. 


\section{Results}

\section{Results from Descriptive Analyses}

Among the 3494 direct care workers in the sample, about $44 \%$ held an occupational credential required by their jobs. As Table 1 presents, the demographic characteristics of direct care workers significantly differed by credential status. Workers with a credential were more likely to be 35 through 65 years old, female, African Americans, married, parent, and foreign-born, compared to those without a credential. A slightly fewer percentage of certified workers lived in a poor family with incomes below $100 \%$ federal poverty lines. When the workers' states of residence were observed by the training standards for home health aides, a higher percentage of credentialed workers than non-credentialed workers lived in a state that required greater hours of training.

Table 2 presents the employment setting of the sample direct care workers by their credential holding. Among all workers in the sample, most workers worked at either nursing care facilities $(29.63 \%)$ or for home health care services $(29.96 \%)$. However, a higher percentage of credentialed $(35 \%)$ than non-credentialed $(26 \%)$ workers were employed in nursing care facilities. A lower percentage $(27 \%)$ of credentialed workers, compared to the non-credentialed (32\%), were employed by home health care services. Most direct care workers were employed by private employers. Among all workers, less than $2 \%$ were directly employed by households or worked as independent contractors, and less than $5 \%$ were employed by state or local governments.

Table 3 shows descriptive findings on the job quality measures: Full-time work status, year-round work status, access to employer-provided health insurance and retirement plans, and annual earning. Approximately $70 \%$ of all direct care workers worked full-time (at least $35 \mathrm{~h}$ per week) and $80 \%$ worked year-round (at least 50 weeks last year). About $40 \%$ of them had access to an employer-provided health insurance plan, and $19 \%$ of them had access to an employer-provided retirement plan. The annual median earnings for the workers were approximately $\$ 22,900$, which was consistent with the statistics discussed above (Bureau of Labor Statistics 2018).

The findings presented in the last two columns of Table 3 indicate that the direct care workers' job qualities differ by their credential holding; Workers with a credential had better job qualities across all the measures than those without. About $78 \%$ of workers with a credential worked full-time, compared to $65 \%$ of those without. Nearly $87 \%$ of credentialed workers worked year-round, but the corresponding percentage was $75 \%$ for non-credentialed workers. About $46 \%$ of credentialed workers compared to $36 \%$ of non-credentialed workers had access to an employer-provided health insurance plan. Similarly, $21 \%$ of credentialed workers compared to $17 \%$ of non-credentialed workers had access to an employer-provided retirement plan. The differences in mean and median annual earnings by credential status were also large and significant. The median annual earnings of workers with a credential were $\$ 4200$ more than that of workers without a credential $(\$ 25,000$ vs. $\$ 20,800, p<.001)$.

\section{Results from Average Treatment Effects (ATE) Models}

Before jumping into the ATE analysis, it was necessary to investigate the covariate balance of the PSM models and examine if the weights in the models improved the 
Table 1 Demographic characteristics of nursing, psychiatric, home health aides, weighted percentage distribution

\begin{tabular}{|c|c|c|c|}
\hline & $\begin{array}{l}\text { All } \\
(N=3494)\end{array}$ & $\begin{array}{l}\text { Without Credential } \\
(N=1951)\end{array}$ & $\begin{array}{l}\text { With Credential } \\
(N=1543)\end{array}$ \\
\hline \multicolumn{4}{|l|}{ Age group } \\
\hline Less than 24 years old & 16.31 & 19.80 & 11.29 \\
\hline $25-34$ & 24.44 & 24.57 & 24.27 \\
\hline $35-44$ & 17.96 & 16.77 & 19.68 \\
\hline $45-54$ & 16.61 & 13.66 & 20.85 \\
\hline $55-64$ & 17.48 & 16.58 & 18.77 \\
\hline 65 or older & 7.19 & 8.62 & 5.14 \\
\hline Female & 88.55 & 85.44 & 93.03 \\
\hline \multicolumn{4}{|l|}{ Race and Ethnicity } \\
\hline White & 42.24 & 42.42 & 41.98 \\
\hline African American & 33.70 & 31.91 & 36.27 \\
\hline Hispanic & 16.91 & 17.75 & 15.70 \\
\hline Others & 7.15 & 7.92 & 6.04 \\
\hline Married & 36.57 & 33.48 & 41.03 \\
\hline Parent & 34.91 & 30.05 & 41.91 \\
\hline \multicolumn{4}{|l|}{ Citizenship } \\
\hline Native-born citizens & 74.90 & 77.17 & 71.62 \\
\hline Naturalized citizens & 14.10 & 12.8 & 15.98 \\
\hline Noncitizens & 11.00 & 10.03 & 12.4 \\
\hline \multicolumn{4}{|l|}{ Education } \\
\hline Less than high school & 7.69 & 8.31 & 6.81 \\
\hline High school & 36.85 & 36.58 & 37.24 \\
\hline Some college & 44.35 & 44.72 & 43.83 \\
\hline College or more & 11.10 & 10.39 & 12.12 \\
\hline \multicolumn{4}{|l|}{ Family poverty } \\
\hline $100 \%$ FPL & 11.75 & 13.52 & 9.20 \\
\hline $200 \%$ FPL & 26.33 & 23.81 & 29.95 \\
\hline $300 \%$ FPL & 23.23 & 22.77 & 23.89 \\
\hline $400 \%$ FPL or higher & 38.70 & 39.91 & 36.96 \\
\hline \multicolumn{4}{|c|}{ Required hours of training for home health aides } \\
\hline $120+$ hours (6 states) & 74.64 & 73.3 & 76.57 \\
\hline 76-119 hours (10 states) & 10.50 & 9.91 & 11.35 \\
\hline 75 hours (34 states + D.C. $)$ & 14.86 & 16.78 & 12.08 \\
\hline
\end{tabular}

balance. When the balance was improved, the weighted versions compared to the unweighted versions generated the following two: (1) the standardized mean differences that are closer to 0 and (1) the variance ratios that are closer to 1 (Lamm and Yung 2017). Table 4 presents covariate differences of the variables commonly included in all PSM models for the five job quality outcome models. It showed improvement in balance after weighting when the unweighted and weighted numbers were compared. 
Table 2 Employment characteristics of nursing, psychiatric, home health aides, weighted percentage distribution

\begin{tabular}{lccc}
\hline & $\begin{array}{l}\text { All } \\
(N=3494)\end{array}$ & $\begin{array}{l}\text { Without Credential } \\
(N=1951)\end{array}$ & $\begin{array}{l}\text { With } \\
\text { Credential } \\
(N=1543)\end{array}$ \\
\hline Employment Setting & & & \\
Nursing care facilities & 29.63 & 25.82 & 35.11 \\
Home health care services & 29.96 & 31.94 & 27.12 \\
Hospitals & 18.32 & 17.85 & 19.00 \\
Residential care facilities & 6.55 & 6.28 & 6.94 \\
Other health care services & 5.64 & 6.54 & 4.35 \\
Individual and family services & 3.38 & 3.96 & 2.55 \\
Outpatient care centers & 2.32 & 3.02 & 1.30 \\
Other industries & 4.19 & 4.59 & 3.62 \\
Employer Type & & & \\
Household or self & 1.75 & 2.29 & 0.97 \\
Private & 93.53 & 93.63 & 93.37 \\
Government & 4.73 & 4.08 & 5.66 \\
\hline
\end{tabular}

Table 5 summarizes the findings of ATE models for all job quality measures. Overall, the occupational credential status of direct care workers was consistently related to better job qualities. Credential holding was positively related to full-time work, year-round work, having access to employer-provided health insurance and retirement saving plans, and more annual earnings.

For each job quality measure, Table 5 shows that the estimated effect of credential holding on the job quality measure for the population of direct care workers. For example, the ATE of 0.0540 of the second row of Table 5 indicates that occupational credential holding was related to a $5.4 \%$ increase in the probability of working full-time $(p<.001)$. Similarly, the credential holding was related to a $7.3 \%$ increase in the probability of working year-round $(p<.001)$.

Table 3 Descriptive statistics on job quality measures, weighted percentages, means, and medians

\begin{tabular}{llll}
\hline & $\begin{array}{l}\text { All } \\
(N=3494)\end{array}$ & $\begin{array}{l}\text { Without Credential } \\
(N=1951)\end{array}$ & $\begin{array}{l}\text { With Credential } \\
(N=1543)\end{array}$ \\
\hline Percent working full-time & 70.19 & 64.70 & 78.10 \\
Percent working year-round & 79.67 & 74.63 & 86.94 \\
Percent with health insurance plan & 39.86 & 35.52 & 46.11 \\
Percent with retirement saving plan & 18.74 & 17.04 & 21.19 \\
Person's annual gross earning (\$) & & & \\
Mean & 23,603 & 22,162 & 25,679 \\
Median & 22,880 & 20,800 & 25,000 \\
\hline
\end{tabular}


Table 4 Covariate differences for Propensity Score Model (PSM)

\begin{tabular}{|c|c|c|c|c|}
\hline & \multicolumn{2}{|c|}{ Standardized Difference } & \multicolumn{2}{|c|}{ Variance Ratio } \\
\hline & Unweighted & Weighted & Unweighted & Weighted \\
\hline Female & -0.0974 & -0.0051 & 0.7667 & 0.9865 \\
\hline \multicolumn{5}{|l|}{ Age (65 or older) } \\
\hline Less than 24 years old & -0.2205 & -0.0121 & 0.6382 & 0.9765 \\
\hline $25-34$ & 0.0204 & 0.0036 & 1.0255 & 1.0045 \\
\hline $35-44$ & 0.0817 & 0.0018 & 1.1286 & 1.0026 \\
\hline $45-54$ & 0.1206 & 0.0075 & 1.2074 & 1.0117 \\
\hline $55-64$ & 0.0432 & 0.0007 & 1.0808 & 1.0012 \\
\hline \multicolumn{5}{|l|}{65 or older } \\
\hline \multicolumn{5}{|l|}{ Race and Ethnicity (other) } \\
\hline White & -0.0076 & 0.0014 & 0.9977 & 1.0004 \\
\hline African American & 0.0307 & 0.0022 & 1.0252 & 1.0018 \\
\hline Hispanic & -0.0107 & 0.0005 & 0.9820 & 1.0008 \\
\hline \multicolumn{5}{|l|}{ Education (college or more) } \\
\hline Less than high school & -0.1035 & -0.0025 & 0.7329 & 0.9927 \\
\hline High school & -0.0655 & -0.0072 & 0.9651 & 0.9960 \\
\hline Some college & 0.1252 & 0.0109 & 1.0289 & 1.0025 \\
\hline \multicolumn{5}{|c|}{ Employment Setting (other industries) } \\
\hline Nursing care facilities & 0.2106 & 0.0006 & 1.1892 & 1.0005 \\
\hline Home health care services & -0.1554 & -0.0085 & 0.8488 & 0.9911 \\
\hline Hospitals & 0.0133 & 0.0026 & 1.0207 & 1.0039 \\
\hline Residential care facilities & 0.0270 & 0.0035 & 1.1044 & 1.0128 \\
\hline Other health care services & -0.0518 & 0.0029 & 0.8135 & 1.0116 \\
\hline Individual and family services & -0.1027 & 0.0019 & 0.5672 & 1.0099 \\
\hline Outpatient care centers & -0.0296 & 0.0021 & 0.8518 & 1.0112 \\
\hline State fixed effects & Included & & Included & \\
\hline
\end{tabular}

Note: Reference groups are in parentheses

The same table also presents that having a credential was related to a higher probability of accessing employer-provided health insurance (by $3.43 \%, p<.05$ ) and a retirement saving plan (by $3.16 \%, p<.05$ ) for direct care workers. According to the last row of the table, credential-holding was also related to an increase in the log of direct care workers' annual earnings by $6.07 \%(p<.01)$. Findings overall showed that credential holding among direct care workers is a significant determinant of all job quality measures and that the effect sizes are in keeping with the findings reported by previous studies discussed above (which showed a range of 5 to $8 \%$ premiums) (Blair and Chung 2018; Gittleman et al. 2018; Kim and Chatterji 2020). Because few empirical evidence exists on the benefits of occupational credentials for job qualities other than wages or earnings, it is difficult to assess if this study's findings on other job quality measures are within the range reported in the literature. Nevertheless, the effect sizes $(5.4 \%$ and $7 \%)$ for full-time work status and year-round work status appear to be 
Table 5 Average treatment effects (ATEs) of occupational certifications on job quality measures for nursing, psychiatric, home health aides

\begin{tabular}{|c|c|c|c|c|c|c|c|c|c|}
\hline Job qualities & Estimate & $\begin{array}{l}\text { Robust } \\
\text { S.E. }\end{array}$ & $\begin{array}{l}\text { Bootstrap } \\
\text { S.E. }{ }^{a}\end{array}$ & $\begin{array}{l}\text { Wald } 95 \\
\text { C.L. }{ }^{\text {b }}\end{array}$ & & $\begin{array}{l}\text { Bootstr } \\
\text { Correct } \\
\text { C.L. }{ }^{b}\end{array}$ & $\begin{array}{l}\text { ap Bias } \\
\text { ed } 95 \%\end{array}$ & $\mathrm{Z}$ & $\operatorname{Pr}>|Z|$ \\
\hline Full-time work status & 0.0540 & 0.0149 & 0.0148 & 0.0248 & 0.0832 & 0.0254 & 0.0820 & 3.62 & 0.0003 \\
\hline Year-round work status & 0.0703 & 0.0133 & 0.0140 & 0.0443 & 0.0964 & 0.0434 & 0.0985 & 5.29 & $<.0001$ \\
\hline $\begin{array}{l}\text { Access to health } \\
\text { insurance }\end{array}$ & 0.0343 & 0.0157 & 0.0156 & 0.0035 & 0.0650 & 0.0035 & 0.0642 & 2.18 & 0.0289 \\
\hline Access to retirement plan & 0.0316 & 0.0136 & 0.0140 & 0.0049 & 0.0583 & 0.0019 & 0.0582 & 2.32 & 0.0204 \\
\hline $\begin{array}{l}\text { Person's annual gross } \\
\text { earning (Logged) }\end{array}$ & 0.0607 & 0.0205 & 0.0228 & 0.0205 & 0.1009 & 0.0145 & 0.1055 & 2.96 & 0.0031 \\
\hline
\end{tabular}

a S.E. stands for standards errors

${ }^{\mathrm{b}}$ C.L. stands for confidence limits

in a range comparable to those reported for wages and earnings. Yet, the effect sizes for employer-provided health and retirement saving plans (3.43 and 3.16\%) seem smaller than those reported for wages and earnings.

\section{Sensitivity Analyses}

A concern could be raised about the sample of this analysis that the direct care jobs are often a secondary source of income for the workers. These workers are less likely to be credentialed, and their job qualities are not as good as those who take the jobs as the primary source of their incomes. A closer look at the sample revealed that $11.7 \%(n=$ 409) of the sample workers had earnings from other sources, but about half of the other earnings were below $\$ 6000$ annually indicating that their direct care jobs were their primary income sources. Only 73 workers in the sample had other earnings greater than the earnings from their direct care jobs. When the ATE models for all outcomes were reanalyzed excluding those 73 workers from the sample, the overall results remained almost the same. The effects of credential holding changed to $5.27 \%$ (from $5.4 \%$ ) for full-time work status, $7.10 \%$ (from $7.03 \%$ ) from year-round work status, $3.41 \%$ (from $3.43 \%$ ) for the probability of accessing health insurance, and $2.85 \%$ (from $3.16 \%$ ) for the probability of having an employer-provided retirement savings plan. The effect of credential holding on annual earning also remained at $5.93 \%$, similar to $6.07 \%$ of the total sample workers. These additional analyses affirm that the results of this study are not sensitive to including direct care workers who hold the jobs as a secondary income source.

Another potentially sensitive item to check is if the regression results are sensitive to the inclusion of employment settings as one of the control variables. As discussed above, if an employment setting can be a mechanism for occupational credentials to generate the labor market premiums for direct care workers, it should not be controlled in the regression analyses (Angrist and Pischke 2008). To investigate if the results of this study are sensitive to controlling for employment setting, additional analyses were 
conducted for all outcome variables excluding the employment setting as one of the control variables. When the results were compared, they were nearly identical to the results presented above, leading to a conclusion that the results are not sensitive to controlling for employment settings (the results of additional analyses are not presented here but will be available upon request).

\section{Discussions and Implications}

The findings of this study showed that occupational credentials are associated with all job quality measures of direct care workers examined in this study. They were related to higher likelihoods of full-time work, year-round work, having access to employerprovided health insurance and retirement saving plans, and earning more annually. These results were robust because the analyses considered differences in the rate of credential-holding and job qualities by employment settings and state variations in credential requirements and job qualities. The overall findings of this study are in keeping with previous research (Howes 2008) that training and credentials are significantly related to the job qualities of direct care workers. Nevertheless, it is important to note that the effects of credential requirements on the job qualities examined in this study were quite modest, which will be discussed later.

A noteworthy limitation of this study is that the data for this study is based on the selfreported status of the occupational credential holding of the CPS respondents. As briefly mentioned above, although it was reported that the measurement errors of the data were insignificant among the employed (Allard 2016), the size of errors for direct care workers is currently unknown given the fact that there are no national statistics on direct care workers' occupational credentials (U.S. Government Accountability Office 2016). Future studies should investigate these measurement issues with the CPS data for direct care workers, perhaps starting with certified nursing aides, for whom states are required to have registries of credentialed workers (U.S. Government Accountability Office 2016). Yet, for such an analysis to be possible, the CPS data should provide a way for researchers to distinguish different types of direct care workers.

Given the importance of job qualities for the direct care workforce supply and stability, the findings of this study have implications for the perennial issue of worker shortages in the industry. First of all, the view that training and credential requirements contribute to rather than mitigate worker shortages is hard to be supported (although it would be important to examine the extent to which state variations in the training and credentialing requirements are related to any variations in the supply of direct care workers in a future study). One less publicized aspect of credential requirements is, as indicated above, that they can help stabilize the direct care workforce supply by enabling historically underrepresented women such as recent immigrants to enter the job market in a more institutionalized way. If job entry in a non-credentialed environment depends on informal networks, individuals who lack social connections can be at a disadvantage (Redbird 2017). In the credentialed industry, on the other hand, the (para)professional institutions can potentially offer workers occupation-specific training and network as well as career-related mentoring with occupation-specific cultural and social capital (Redbird 2017). By institutionalizing the path to job preparation and entry, training and credentials may make the 
occupation more accessible at least for some groups. Although the credential-related labor market premiums could be greater for recently immigrated women, this potential sheepskin effect could not be tested because the current CPS data do not provide a large enough sample size for the group. A future study with more years of data to be pooled should investigate this effect.

According to Lerman et al. (2014), training and credentialing are key to addressing the three challenges of the long-term care industry simultaneously: increasing worker retention, increasing wages, and improving service qualities, while not necessarily increasing the costs of care. Although training and credentialing may be crucial, the size of their impacts should not be overrated given the findings of this study. Regardless of credential-holding, all direct care workers have limited earnings and employment benefits, and the estimated improvement in job qualities associated with credential-holding is not substantial. Strategies other than training and credentialing are called for - such as raising the wage and benefit levels and creating a career lattice - to improve the job quality of the direct care workforce.

Stakeholders in the long-term care industry - insurers, employers, consumers, and public policymakers - may have economic self-interest in keeping the wages and benefits low for the direct care workforce. Raising the wage and benefit floors of the direct care workforce, however, can be cost saving in the long run by lowering the costs related to high turnover and potentially improving clients' health outcomes and satisfaction (Dawson 2016). High turnover rates increase the economic burden on agencies and consumers. Agencies need to bear the expenses of recruiting, training, and reassigning new workers along with any costs related to losing workers who have the knowledge, experiences, and relationships specific to their consumers. High turnover rates can also increase service interruption and related emotional burden and dissatisfaction among consumers, which may affect the quality of care and consumer's life outcomes (Sengupta et al. 2010). Reducing turnover-related costs and improving consumers' outcomes may lead to overall cost-saving for the industry.

A career lattice through the development of specialized skill areas can enable direct care workers to take on additional responsibilities for higher wages (Osterman 2019) or identify upward and lateral career mobility opportunities within the industry (Dawson 2016; Dill and Morgan 2018). For example, certified nursing aides can make a lateral movement to the nursing department that can offer substantial upward mobility for the workers and then later move up a career ladder to be Licensed Practical Nurses (Dill and Morgan 2018). This career ladder between direct care workers and nurses can be offered to a subset of "advanced aides" to create specialized direct care workers with additional responsibilities. As Rivas et al. (Ribas et al. 2012) warned, however, the career ladder for direct care workers cannot be counted for the vast majority of workers and is currently not prevalent in the industry (Ribas et al. 2012). Perhaps expanding the role of direct care workers and allowing them to perform - with adequate training - some of the tasks delegated by nurses may be a more effective way to increase their job quality and reduce the costs of long-term care. As worker shortages in the direct care industry are projected to intensify in the coming decades (Dawson 2016; Osterman 2019), it remains to be seen how the stakeholders of the direct care industry will resolve the job quality problems to address worker shortages. 


\section{Compliance with Ethical Standards}

Ethics Approval This study used publicly available existing data and no ethical approval was required.

Informed Consent This study is a secondary analysis of existing data; human subjects and informed consent were not required.

Conflict of Interest The author declares no conflict of interest.

\section{References}

Albert K (2017) The certification earnings premium: an examination of young workers. Soc Sci Res 63:138149. https://doi.org/10.1016/j.ssresearch.2016.09.022

Allard MD (2016) Adding questions on certifications and licenses to the current population survey. Monthly Labor Review, 1-16. https://stats.bls.gov/opub/mlr/2016/article/pdf/adding-questions-on-certificationsand-licenses-to-the-current-population-survey.pdf

American Health Care Association \& National Center for Assisted Living (2020). Temporary Nurse Aids Training and Competency Checklist. https:/www.ahcancal.org/facility_operations/disaster_planning/ Documents/COVID-19\%20\%E2\%80\%93\%20Update\%2027.pdf

Angrist JD, Pischke JS (2008) Mostly harmless econometrics: an empiricist's companion. Princeton university press

Appelbaum E, Leana C (2011) Improving job quality: direct care workers in the US. Center for Economic Policy and Research. https://doi.org/10.13140/RG.2.1.4074.1209

Blair PQ, Chung BW (2018) Job market signaling through occupational licensing (no. w24791). National Bureau of Economic Research. https:/www.nber.org/papers/w24791

Brookhart MA, Schneeweiss S, Rothman KJ, Glynn RJ, Avorn J, Stürmer T (2006) Variable selection for propensity score models. Am J Epidemiol 163(12):1149-1156. https://doi.org/10.1093/aje/kwj149

Dawson SL (2016) The SEIU healthcare NW training partnership in Washington state. Generations 40(1):88$91 \mathrm{https}: / /$ search.proquest.com/docview/1797672727/fulltextPDF/35476D8AF56D4004PQ/1 ?accountid= 13314

Dawson SL, Surpin R (2001) Direct-care healthcare workers: you get what you pay for. Generations 25(1):23$28 \mathrm{https}: / /$ phinational.org/wp-content/uploads/legacy/clearinghouse/Gen-DawSur.pdf

Dill JS, Morgan JC (2018) Employability among low-skill workers: organizational expectations and practices in the US health care sector. Hum Relat 71(7):1001-1022. https://doi.org/10.1177/0018726717734035

Folbre N (2006) Demanding quality: worker/consumer coalitions and "high road" strategies in the care sector. Polit Soc 34(1):11-32. https://doi.org/10.1177/0032329205284754

Franzosa E, Tsui EK, Baron S (2018) Home health aides' perceptions of quality care: goals, challenges, and implications for a rapidly changing industry. New Solutions 27(4):629-647. https://doi.org/10.1177/ 1048291117740818

Gittleman M, Klee MA, Kleiner MM (2018) Analyzing the labor market outcomes of occupational licensing. Industrial Relations: A Journal of Economy and Society 57(1):57-100. https://doi.org/10.1111/irel.12200

Howes C (2008) Love, money, or flexibility: what motivates people to work in consumer-directed home care? The Gerontologist 48(suppl 1):46-60. https://doi.org/10.1093/geront/48.supplement_1.46

Institute of Medicine (2008) Retooling for an aging America: building the health care workforce. Washington D.C.: National Academies Press. https:/www.ncbi.nlm.nih.gov/books/NBK215401/pdf/Bookshelf NBK215401.pdf

Kelly CM, Morgan JC, Jason KJ (2013) Home care workers: interstate differences in training requirements and their implications for quality. Journal of Applied Gerontology 32(7):804-832. https://doi.org/10. $1177 / 2$ F0733464812437371

Kim J (2020) Informal employment and earnings of home-based home care workers in the United States. Ind Relat J 51(4):283-300. https://doi.org/10.1111/irj.12299

Kim J, Chatterji S (2020) Gender and educational variations in the earnings premiums of occupational credentials. The BE Journal of Economic Analysis \& Policy, 1(ahead-of-print). https://doi.org/10.1515/ bejeap-2019-0187 
Kleiner MM, Krueger AB (2010) The prevalence and effects of occupational licensing. Br J Ind Relat 48(4): 676-687. https://doi.org/10.1111/j.1467-8543.2010.00807.x

Kleiner MM, Park KW (2010) Battles among licensed occupations: Analyzing government regulations on labor market outcomes for dentists and hygienists (no. w16560). National Bureau of Economic Research. https://www.nber.org/papers/w16560.pdf

Lamm M, Yung YF (2017) Estimating causal effects from observational data with the CAUSALTRT procedure. Cary, NC: SAS Institute. https://support.sas.com/resources/papers/proceedings17/SAS03742017.pdf

Law MT, Marks MS (2009) Effects of occupational licensing laws on minorities: evidence from the progressive era. J Law Econ 52(2):351-366. https://doi.org/10.1086/596714

Lerman RI, Eyster L, Kuehn D (2014) Can we upgrade low-skill, low-wage occupations? The case of apprenticeships in the long-term care occupations. Journal of Women, Politics and Policy 35(2):110 132. https://doi.org/10.1080/1554477X.2014.890835

MacAdam M (1993) Home care reimbursement and effects on personnel. Gerontologist 33(1):55-63. https:// doi.org/10.1093/geront/33.1.55

McMullen TL, Resnick B, Chin-Hansen J, Geiger-Brown JM, Miller N, Rubenstein R (2015) Certified nurse aide scope of practice: state-by-state differences in allowable delegated activities. J Am Med Dir Assoc 16(1):20-24. https://doi.org/10.1016/j.jamda.2014.07.003

Menne HL, Ejaz FK, Noelker LS, Jones JA (2007) Direct care workers' recommendations for training and continuing education. Gerontology \& Geriatrics Education 28(2):91-108. https://doi.org/10.1300/ J021v28n02_07

New Jersey Board of Nursing (2020). Certified Homemaker-Home Health Aides: Statues and Regulations. https://www.njconsumeraffairs.gov/hhh/Pages/regulations.aspx

Nguyen V (2017) Long-term support and services. Fact sheet. Washington: AARP Public Policy Institute. https:/www.aarp.org/content/dam/aarp/ppi/2017-01/Fact\%20Sheet\%20Long-Term\%20Support\% 20 and $\% 20$ Services.pdf

Osterman P (2008) Improving the quality of low-wage work: the current American experience. International Labour Review 147(2-3):115-134. https://doi.org/10.1111/j.1564-913X.2008.00028.x

Osterman P (2019) Improving job quality for direct care workers. Econ Dev Q 33(2):151-156. https://doi.org/ $10.1177 / 0891242418777355$

Paraprofessional Healthcare Institute (2018) U.s. Home Care Workers: Key Facts https://phinational.org/ resource/u-s-home-care-workers-key-facts-2018/

Paraprofessional Healthcare Institute. (2016a) Nurse aid training requirements. https://phinational.org/wpcontent/uploads/2017/07/na-training-reqs.pdf

Paraprofessional Healthcare Institute. (2016b) Home health aides training requirements by state. https:// phinational.org/advocacy/home-health-aide-training-requirements-state-2016/

Pizzola B, Tabarrok A (2017) Occupational licensing causes a wage premium: evidence from a natural experiment in Colorado's funeral services industry. Int Rev Law Econ 50:50-59. https://doi.org/10.1016/ j.irle.2017.04.005

Redbird B (2017) The new closed shop? The economic and structural effects of occupational licensure. Am Sociol Rev 82(3):600-624. https://doi.org/10.1177/0003122417706463

Ribas V, Dill JS, Cohen PN (2012) Mobility for care workers: job changes and wages for nurse aides. Soc Sci Med 75(12):2183-2190. https://doi.org/10.1016/j.socscimed.2012.08.015

SAS (2016) SAS/STAT 14.2 User's guide: the CAUSALTRT procedures. Cary, NC: SAS Institute. https:// support.sas.com/documentation/onlinedoc/stat/142/causaltrt.pdf

Sengupta M, Harris-Kojetin LD, Ejaz FK (2010) A national overview of the training received by certified nursing assistants working in U.S. nursing homes. Gerontol Geriatr Educ 31(3):201-219. https://doi.org/ $10.1080 / 02701960.2010 .503122$

Severns, M. (2020) Trump team relaxed training rules for nursing home staff just as pandemic hit. Politico. https://www.politico.com/news/2020/07/15/coronavirus-nursing-homes-361510

Smith K, Baughman R (2007) Caring for America's aging population: a profile of the direct-care workforce. Monthly Labor Review 130:20 https:/www.bls.gov/opub/mlr/2007/09/art3full.pdf

Stone RI (2004) The direct care worker: the third rail of home care policy. Annu Rev Public Health 25(1):521537. https://doi.org/10.1146/annurev.publhealth.25.102802.124343

Stone RI, Dawson SL (2008) The origins of better jobs better care. The Gerontologist 48(suppl 1):5-13. https://doi.org/10.1093/geront/48.supplement_1.5

Temple A, Dobbs D, Andel R (2009) Exploring correlates of turnover among nursing assistants in the National Nursing Home Survey. Health Care Manag Rev 34(2):182-190. https://doi.org/10.1097/HMR. $0 \mathrm{~b} 013 \mathrm{e} 31819 \mathrm{c} 8 \mathrm{~b} 11$ 
Thornton RJ, Timmons EJ (2013) Licensing one of the world's oldest professions: massage. J Law Econ 56(2):371-388. https://doi.org/10.1086/667840

Timmons EJ, Thornton RJ (2008) The effects of licensing on the wages of radiologic technologists. J Lab Res 29(4):333-346. https://doi.org/10.1007/s12122-007-9035-9

U.S. Bureau of Labor Statistics (2018) May 2017 National Occupational Employment and Wage Estimates. https://www.bls.gov/oes/2017/may/oes_nat.htm\#31-0000

U.S. Bureau of Labor Statistics (2019) Occupational Outlook Handbook: Fastest growing occupations. https:// www.bls.gov/ooh/fastest-growing.htm

U.S. Census Bureau. (2020). Current Population Survey 2019 Annual Social and Economic (ASEC) Supplement. https://www2.census.gov/programs-surveys/cps/techdocs/cpsmar19.pdf

U.S. Government Accountability Office (2016). Long-term care workforce: Better information needed on nursing assistants, home health aides, and other direct care workers. https://www.gao.gov/assets/680/ 679100.pdf

Publisher's Note Springer Nature remains neutral with regard to jurisdictional claims in published maps and institutional affiliations. 